\title{
Magnetic resonance mammography in comparison with mammography in the discovery of multifocal, multicentric and bilateral lesions of breast cancer
}

\author{
Khadijeh Bakhtavar ${ }^{1}$, Maryam Saran², Masoud Behzadifar ${ }^{3}$, Maryam Farsi $^{4}$
}

${ }^{1}$ MD, Assistant Professor, Department of Radiology, Faculty of Medicine, Tehran University Medical of Sciences, Tehran, Iran

${ }^{2}$ MD, Resident of Radiology, Department of Radiology, Faculty of Medicine, Tehran University Medical of Sciences, Tehran, Iran

${ }^{3} \mathrm{PhD}$ Student, Health Management and Economics Research Center, Iran University of Medical Sciences, Tehran, Iran

${ }^{4}$ MA, Department of Radiology, Sina Hospital, Tehran University Medical of Sciences, Tehran, Iran

\section{Type of article: Original}

\begin{abstract}
Background: Breast cancer is one of the health system problems and important diseases that is rising in developing and advanced countries.

Objective: This study aimed to determine the difference of Magnetic Resonance Mammography (MRM) findings versus mammography in detecting multifocal, multi-centric and malignant bilateral lesions in patients with known breast cancer in Tehran.

Methods: This cross-sectional study was conducted in Iran and Tehran among breast cancer patients between January 2015 and February 2016. Patients were included in the study prior to surgery, at the request of a surgeon with the aim of detecting multifocal, multi-centric and bilateral lesions. Demographic information was also collected from patients. The results for quantitative variables were expressed as mean and standard deviations, and for qualitative variables, were expressed as relative and absolute frequency. Chi-square test was used to compare the two methods. SPSS Ver.24 (IBM) software was used to analyze the data.

Results: Thirty-nine patients were enrolled in the study. The mean age of patients in this study was $48.46 \pm 6.836$. In mammography, $13(33.3 \%)$ had Composition $\mathrm{C}$ and $26(66.7 \%)$ had Composition D according to the type of Composition. In total, 25 patients $(89.3 \%)$ had one lesion and 3 patients $(10.7 \%)$ had more than two lesions. In MRM, all lesions observed were mass (54 masses). The number of lesions found in MRM was 27 patients with one lesion (58.9\%), 6 patients with two lesions (20.5\%) and 5 patients with three lesions (20.6\%). MRM detected more lesions compared to mammography $(\mathrm{p}<0.0001)$. The value of Chi-square test with a degree of freedom and error level of 0.05 was 3.71 and $p<0.0001$ that showed a significant relationship between the number of MRM findings in comparison with mammography.

Conclusion: The results of our study showed that two or more lesions and bilateral lesions in MRM were more than mammography in women with B Breast Composition C, D; the findings showed that MRM has a better ability to detect breast masses, and can affect the patient's surgical procedure.

Keywords: Breast cancer, Mammography, MRM, Multifocal, Multi-centric, Bilateral
\end{abstract}

\section{Introduction}

Breast cancer is one of the health system problems and important diseases that is rising in developing and advanced countries. The most common cancer among women is breast cancer, which causes 522,000 deaths per year among women (1). In developing countries, the first cause of death in women is breast cancer (2). Breast cancer is

\section{Corresponding author:}

Dr. Maryam Saran, Department of Radiology, Faculty of Medicine, Tehran University Medical of Sciences, Tehran, Iran. Tel: +98.9161597816, Fax: +98.2166123744, Email: dr.sms64@yahoo.com

Received: May 12, 2017, Accepted: July 27, 2017, Published: August 2017

iThenticate screening: July 10, 2017, English editing: August 15, 2017, Quality control: August 17, 2017

This article has been reviewed / commented by three experts

(C) 2017 The Authors. This is an open access article under the terms of the Creative Commons Attribution-NonCommercialNoDerivs License, which permits use and distribution in any medium, provided the original work is properly cited, the use is non-commercial and no modifications or adaptations are made. 
increasing in many parts of the world, and this has been a concern for health policymakers worldwide (3). Like many other countries in the world, Iran faces this disease as a major challenge. Studies have been performed on the prevalence of this disease in women. In a study conducted in Iran, the incidence of breast cancer was reported to be $0.5 \%$ (4). The World Health Organization (WHO) in its report in 2014, stated that $14.2 \%$ of deaths from cancer were among women due to breast cancer (5). In another study conducted in Iran, breast cancer in Iranian women was 24.6\% (6). Various factors such as family history, late menopause, obesity, uterine myoma, dyslipidemia, hypertension, lifestyle changes, and increasing urbanization are considered as risk factors affecting the onset of this disease (7). Unfortunately, breast cancer is diagnosed late in low-income and middle-income countries. Early diagnosis of breast cancer plays an important role in controlling the disease and preventing the increase of mortality in women. Breast cancer screening is cost effective for countries' health systems, and reduces the cost of treatment (8). Screening is often performed each year for women with a positive family history of breast cancer before the age of fifty, with mammography aimed at preventing and reducing their mortality risk. Screening for mammography should be started from the age of forty. It is usually recommended that mammography should be performed every three years after 75 years. In women whose close relatives have had a history of breast cancer such as mother, sister or daughter, the age at which the mammography begins is five years earlier than the age of the affected person. Mammography with ultrasound is done in short intervals (9). Mammography has a different sensitivity in detecting congested tissues and cancer-related lesions (10). Magnetic Resonance Mammography (MRM) of the breast provides three-dimensional information about the tissue and breast cancer to radiologists and is more sensitive than mammography for the detection of lesions (11). Various studies have been carried out to determine the diagnostic power of both mammographic and MRM methods worldwide, which have compared these two for better and more diagnosis of lesions and tissues from breast cancer $(10,12,13)$. The detection of multifocal and multi-centric cases has a significant effect on the decision-making of the type of treatment and care for patients. Detection of these cases causes the type of treatment to vary depending on the physician's view, which can reduce the treatment time and reduce the use of drugs and thus, reduce the side effects of the drug. A short course of treatment also reduces the cost of the treatment. Multifocal cancer arises when two or more lesions of a cancer are present simultaneously in a quadrant or at a distance of less than $5 \mathrm{~cm}$ in different quadrants of a breast. Multi-centric cancer arises when two or more lesions of cancer are present in separate quadrants, or at a distance of more than $5 \mathrm{~cm}$ in a quadrant. Bilateral cancer arises when cancer lesions are present in both breasts $(14,15)$. Diagnostic tests can be a valuable help to better diagnosis and more effective treatment of patients. Differences in diagnostic tests are normal and can lead to a patient's assessment based on tests that can be better diagnosed and show more problems due to the disease, depending on the physician's viewpoint. Therefore, physicians try to use tests that show more lesions and complications (16). The use of MRM and mammography in the diagnosis of breast cancer is used in most countries of the world (17). These two methods are also used in Iran, but still, a study comparing these two methods to detect lesions has not been conducted, and doing studies in this field seems necessary. Considering the increased mortality rate due to breast cancer in Iran, (18) and the role of diagnostic tests in providing better complications and problems that a disease can cause to a person, the aim of this study was to determine the difference between MRM findings versus mammography in the detection of multifocal, multi-centric and malignant bilateral lesions in patients with known breast cancer at Sina Hospital in Tehran, Iran.

\section{Material and Methods}

This was a cross-sectional study. Patients were referred to Sina Hospital in Tehran and from among available items between January 2015 and February 2016. This study was conducted by obtaining an ethical code from the Tehran University of Medical Sciences Ethics Committee with No. (IR.TUMS.REC.1394.1317). Participants in this study were female patients with newly diagnosed breast cancer, confirmed with biopsy. Patients underwent MRM with and without contrast (Gadolinium $0.1 \mathrm{mmol} / \mathrm{kg}$ ) prior to any surgical procedure, at the request of a surgeon (with the aim of detecting multifocal, multi-centric, and bilateral lesions, especially in Mammographically dense patients). MRM was performed with sequences T1, T1 + GAD, T2, T2 FAT SAT. All sequences were performed in axial and sagittal sections. The probable new lesions found in MRM were compared to mammography in the Breast Imaging Reporting and Data System (BIRADS) and lesions with BIRADS 4 and 5 under biopsy. In Standard Views Mammography, the mediolateral oblique (MLO) and craniocaudal (CC) were performed. The results of MRM and mammography of patients, which indicate the presence of breast cancer, were compared in terms of the number of cancer lesions found in each one and in the number of patients in whom lesions were found. For lesions that were shaped in benign or malignant form, but with enhancement, the curve of enhancement was also used. Also, demographic information was collected from patients. Data was entered into the SPSS Ver.24 (IBM) software. The results for quantitative variables were expressed as mean and standard deviations, and for qualitative variables, were expressed as relative and absolute frequency. Chi-square test was used to compare the two methods. Independent t- 
test was used to compare the mean of quantitative variables. The significance level was considered to be less than 0.05 .

\section{Results}

After reviewing patients' records, 39 patients were finally enrolled in the study. Patients whose information was incomplete or who did not want to collaborate after contact with them, were excluded. The mean age of patients in this study was $48.46 \pm 6.836$ years $(30-65)$.

\subsection{Patients' findings based on mammography}

Based on the type of composition, $13(33.3 \%)$ had Composition C and $26(66.7 \%)$ had Composition D. Based on the results of a total of 34 Mass, 11 Asymmetry, 6 Micro calcification, and 14 Architectural distortions were observed. In all patients with Micro calcification and Architectural distortion, there were associated findings, including Mass and Asymmetry. Based on the types of asymmetry observed in mammography, $11(100 \%)$ were Focal. There were 25 patients $(89.3 \%)$ who had one lesion and three patients $(10.7 \%)$ who had more than two lesions (each with three lesions). The types of masses found were based on Margin, of which there were 19 (55.8\%) Obscured, 12 (35.2\%) Indistinct, and $3(9 \%)$ Speculated. The disease was not seen with Circumscribed and Micro-lobulated mass. Considering the types of masses found based on shape in mammography, 21 cases $(61.7 \%)$ were Irregular, 8 cases (23.5\%) Oval and 5 cases (14.8\%) Round. Chi-square test showed that there was a significant relationship between MRM findings compared to mammography (degree of freedom and error level of 0.05 was 3.71 and p- value was smaller than 0.0001).

\subsection{Patients' findings based on MRM}

In MRM, all lesions observed were mass (54 masses). The number of lesions found in MRM was 27 patients with one lesion $(58.9 \%), 6$ patients with two lesions $(20.5 \%)$ and 5 patients with three lesions $(20.6 \%)$. Considering the types of masses based on shape in MRM, 29 cases (53.7\%) were irregular, 11 cases (20.7\%) lobulated, 8 cases $(15 \%)$ round and 6 cases $(10.6 \%)$ oval. Considering the types of masses found based on margin in MRM, 26 cases (48.1\%) were speculated, 21 cases $(38.8 \%)$ irregular and 7 cases $(13.1 \%)$ circumscribed. The masses found in the T2 signal in MRM were $42(77.7 \%)$ low mass, and $12(22.3 \%)$ heterogeneous mass. There was no high mass. The distribution of curve of enhancement in MRM was 29 cases $(53.7 \%)$ of type 3, 16 cases $(29.6 \%)$ of type 2 and 9 cases $(16.7 \%)$ of type 1 .

\section{Discussion}

Breast cancer is one of the most premature and preventable cancers which can be prevented by reducing the mortality rate among patients, increasing survival, and improving the life quality of patients through proper diagnostic strategies. Using screening tests that are regularly used in normal people aged 40 and in people with high risk symptoms and in early stages of the disease, the cancer cells in the breast can be detected before the invasion in early stages (19). The findings of our study showed that MRM sensitivity was higher than mammography in detecting two and more lesions. In various studies conducted in different parts of the world, MRM sensitivity in detecting lesions was higher than mammography which is consistent with the results of this study (20-22). The findings of this study showed that lesions found in patients with mammography were as follows: 28 (62.3\%) with mass, $11(24.5 \%)$ had asymmetry, $6(13.2 \%)$ had micro-calcification, and 14 patients had asymmetry and concurrent masses of architectural distortion. In MRM, all lesions found were mass. In mammography, of patients whose lesions were mass, 25 patients $(89.3 \%)$ had one lesion and 3 patients $(10.7 \%)$ had more than two lesions. The total mass found in 28 patients with a mass in mammography was 34. In MRM, 27 patients (58.9\%) had one lesion, 6 patients $(20.5 \%)$ had two lesions and 5 patients $(20.5 \%)$ had three lesions. Most multifocal and multi-centric and contralateral cases were detected with MRM. The total mass found in MRM was 54. In our study, MRM sensitivity was higher in detecting two or more lesions than mammography. In various studies conducted in different parts of the world, MRM sensitivity in detecting lesions was higher than mammography which is consistent with the results of the present study. According to the findings, mammography found more than one lesion in $7.69 \%$ of all patients, while MRM found more than one lesion in 33.4\% of all patients which was statistically significant. The main reason for this statistically significant difference can be the reduction of mammographic diagnostic sensitivity in the detection of lesions in breast Composition C, D (population studied). Findings detected in MRM in this study were more and more obvious compared to mammography. MRM imaging uses a magnetic field - radio waves and a computer for creating detailed images of organ, soft tissue, bone and other body structures. Thorough details and detailed MRM images allow the physician to better assess some members, and certainly diseases that are not well recognized by other imaging techniques, such as mammography, are taken through early detection and treatment 
measures with this method (23). In three patients with more than two lesions in mammography, all three cases were observed at low intervals and in a quadrant (multifocal). Among patients with two lesions in MRM (6 patients), all cases were unilateral multifocal. Of the 5 patients that had more than two lesions, two patients were simultaneously multifocal-bilateral and multi-centric-bilateral. The lesions were multifocal in three other patients. The findings of the present study emphasize the higher accuracy of MRM in comparison with mammography. In several studies conducted worldwide, the higher accuracy of MRM is emphasized as well $(24,25)$. MRM can provide favorable images of women with dense breast tissue, which is not possible in mammography. The probability of diagnosis of multifocal and multi-centric masses is very high by the MRM method, but mammography still has a primary and basic role. MRM is also a very good tool for detecting very small tumors within the breast (26). This study has some limitations that can be considered as a lack of full access to some patients' records and low sample size of entered patients. We also had financial and time constraints for tracking patients in this study. Breast cancer screening is important due to its consequences for women's health and it is imperative that all health systems use screening methods according to their own conditions. Screening in high-risk women also has double significance.

\section{Conclusions}

The findings of our study indicate that two or multiple and bilateral lesions in MRM were more than mammography in women with Breast Composition C, D more. Its diagnostic power was more effective than that of mammography, and this is a valuable help to physicians. The results of this study can help the process of changing the treatment and surgery in these patients. It is suggested that more women with breast cancer are screened for more information, and a comparison of these two methods will be more valuable and more reliable for physicians. The results of this study could change the course of treatment and surgery in these patients. It is suggested that more women with breast cancer are screened for more information, and a comparison of these two methods with more numbers will provide more valuable and more reliable evidence for physicians.

\section{Acknowledgments:}

This study is part of a residency's thesis of radiology that the corresponding author (Dr. Maryam Saran) conducted with the support of the Radiology Department of Tehran University of Medical Sciences. We appreciate all of the people who assisted us in conducting this study.

\section{Conflict of Interest:}

There is no conflict of interest to be declared.

\section{Authors' contributions:}

All authors contributed to this project and article equally. All authors read and approved the final manuscript.

\section{References:}

1) Shaukat U, Ismail M, Mehmood N. Epidemiology, major risk factors and genetic predisposition for breast cancer in the Pakistani population. Asian Pac J Cancer Prev. 2013; 14(10): 5625-9. doi: 10.7314/APJCP.2013.14.10.5625. PMID: 24289553.

2) Elgaili EM, Abuidriss D, Rahman M, Michalek AM, Mohammed SI. Breast cancer burden in central Sudan. Int J Womens Health. 2010; 9(2): 77-82. PMID: 21072300 , PMCID: PMC2971742.

3) Lin CH, Chuang PY, Chiang CJ, Lu YS, Cheng AL, Kuo WH, et al. Distinct clinicopathological features and prognosis of emerging young-female breast cancer in an East Asian country: a nationwide cancer registry-based study. Oncologist. 2014; 19(6): 583-91. doi: 10.1634/theoncologist.2014-0047. PMID: 24807917, PMCID: PMC4041679.

4) Haghighi F, Mohammadifard M, Naseh G, Hashem K, Saadatjoo SA. Prevalence of breast cancer among women over 30 years in Birjand between 2009 and 2010. J Birjand Univ Med Sci. 2013; 20(1): 68-76.

5) World Health Organization. Cancer country profiles 2014. 2014. Available from: http://www.who.int/cancer/country-profiles/en/.

6) Jazayeri SB, Saadat S, Ramezani R, Kaviani A. Incidence of primary breast cancer in Iran: Ten-year national cancer registry data report. Cancer Epidemiol. 2015; 39(4): 519-27. doi: 10.1016/j.canep.2015.04.016. PMID: 26070507.

7) Chuang SC, Wu GJ, Lu YS, Lin CH, Hsiung CA. Associations between Medical Conditions and Breast Cancer Risk in Asians: A Nationwide Population-Based Study in Taiwan. PLoS One. 2015; 10(11): e0143410. doi: 10.1371/journal.pone.0143410. PMID: 26605792, PMCID: PMC4659594. 
8) World Health Organization. Breast cancer: prevention and control 2017. Available from: http://www.who.int/cancer/detection/breastcancer/en/.

9) Maurice A, Evans DG, Affen J, Greenhalgh R, Duffy SW, Howell A. Surveillance of women at increased risk of breast cancer using mammography and clinical breast examination: Further evidence of benefit. Int $\mathrm{J}$ Cancer. 2012; 131(2): 417-25. doi: 10.1002/ijc.26394. PMID: 21898384.

10) Lord SJ, Lei W, Craft P, Cawson JN, Morris I, Walleser S, et al. A systematic review of the effectiveness of magnetic resonance imaging (MRI) as an addition to mammography and ultrasound in screening young women at high risk of breast cancer. Eur J Cancer. 2007; 43(13): 1905-17. doi: 10.1016/j.ejca.2007.06.007. PMID: 17681781.

11) King V, Brooks JD, Bernstein JL, Reiner AS, Pike MC, Morris EA. Background parenchymal enhancement at breast MR imaging and breast cancer risk. Radiology. 2011; 260(1): 50-60. doi: 10.1148/radiol.11102156. PMID: 21493794.

12) Yang SN, Li FJ, Liao YH, Chen YS, Shen WC, Huang TC. Identification of Breast Cancer Using Integrated Information from MRI and Mammography. PLoS One. 2015; 10(6): e0128404. doi: 10.1371/journal.pone.0128404. PMID: 26056841, PMCID: PMC4461246.

13) Saadatmand S, Rutgers EJ, Tollenaar RA, Zonderland HM, Ausems MG, Keymeulen KB, et al. Breast density as indicator for the use of mammography or MRI to screen women with familial risk for breast cancer (FaMRIsc): a multicentre randomized controlled trial. BMC Cancer. 2012; 12: 440. doi: 10.1186/1471-2407-12-440. PMID: 23031619, PMCID: PMC3488502.

14) Shaikh T, Tam TY, Li T, Hayes SB, Goldstein L, Bleicher R, et al. Multifocal and multicentric breast cancer is associated with increased local recurrence regardless of surgery type. Breast J. 2015; 21(2): 121 6. doi: 10.1111/tbj.12366. PMID: 25597248.

15) Zhou M, Tang Z, Li J, Fan J, Pang Y, Yang H, et al. Clinical and Pathologic Features of Multifocal and Multicentric Breast Cancer in Chinese Women: A Retrospective Cohort Study. J Breast Cancer. 2013; 16(1): 77-83. doi: 10.4048/jbc.2013.16.1.77. PMID: 23593086, PMCID: PMC3625774.

16) Elmore JG, Armstrong K, Lehman CD, Fletcher SW. Screening for Breast Cancer. JAMA. 2005; 293(10): 1245-56. doi: 10.1001/jama.293.10.1245. PMID: 15755947, PMCID: PMC3149836.

17) Riedl CC, Luft N, Bernhart C, Weber M, Bernathova M, Tea MK, et al. Triple-modality screening trial for familial breast cancer underlines the importance of magnetic resonance imaging and questions the role of mammography and ultrasound regardless of patient mutation status, age, and breast density. J Clin Oncol. 2015; 33(10): 1128-35. doi: 10.1200/JCO.2014.56.8626. PMID: 25713430, PMCID: PMC5526626.

18) Enayatrad M, Amoori N, Salehiniya H. Epidemiology and Trends in Breast Cancer Mortality in Iran. Iran J Public Health. 2015; 44(3): 430-1.

19) Brooke HL, Ringbäck Weitoft G, Talbäck M, Feychting M, Ljung R. Adult children's socioeconomic resources and mothers' survival after a breast cancer diagnosis: a Swedish population-based cohort study. BMJ Open. 2017; 7(3): e014968.

20) Pediconi F, Catalano C, Roselli A, Dominelli V, Cagioli S, Karatasiou A, et al. The challenge of imaging dense breast parenchyma: is magnetic resonance mammography the technique of choice? A comparative study with x-ray mammography and whole-breast ultrasound. Invest Radiol. 2009; 44(7): 412-21. doi: 10.1097/RLI.0b013e3181a53654. PMID: 19448554.

21) Adrada B, Arribas E, Gilcrease M, Yang WT. Invasive micropapillary carcinoma of the breast: mammographic, sonographic, and MRI features. AJR Am J Roentgenol. 2009; 193(1): W58-63. doi: 10.2214/AJR.08.1537. PMID: 19542384.

22) Saha S, Sirop S, Korant A, Kanaan M, Shekher R, Strahle D, et al. Nodal positivity in breast cancer correlated with the number of lesions detected by magnetic resonance imaging versus mammogram. Am J Surg. 2011; 201(3): 390-4. doi: 10.1016/j.amjsurg.2010.11.006. PMID: 21367385.

23) Morrow M, Waters J, Morris E. MRI for breast cancer screening, diagnosis, and treatment. Lancet. 2011; 378(9805): 1804-11. doi: 10.1016/S0140-6736(11)61350-0. PMID: 22098853.

24) Boetes C, Veltman J, van Die L, Bult P, Wobbes T, Barentsz JO. The role of MRI in invasive lobular carcinoma. Breast Cancer Res Treat. 2004; 86(1): 31-7. doi: 10.1023/B:BREA.0000032921.10481.dc. PMID: 15218359.

25) Lehman CD, Smith RA. The role of MRI in breast cancer screening. J Natl Compr Canc Netw. 2009; 7(10): 1109-15. doi: 10.6004/jnccn.2009.0072. PMID: 19930977.

26) Ojeda-Fournier H, Comstock CE. MRI for breast cancer: Current indications. Indian J Radiol Imaging. 2009; 19(2): 161-9. doi: 10.4103/0971-3026.48431. PMID: 19881077, PMCID: PMC2765174. 